\title{
Premorbid adjustment amongst outpatients with schizophrenia in a Nigerian psychiatric facility
}

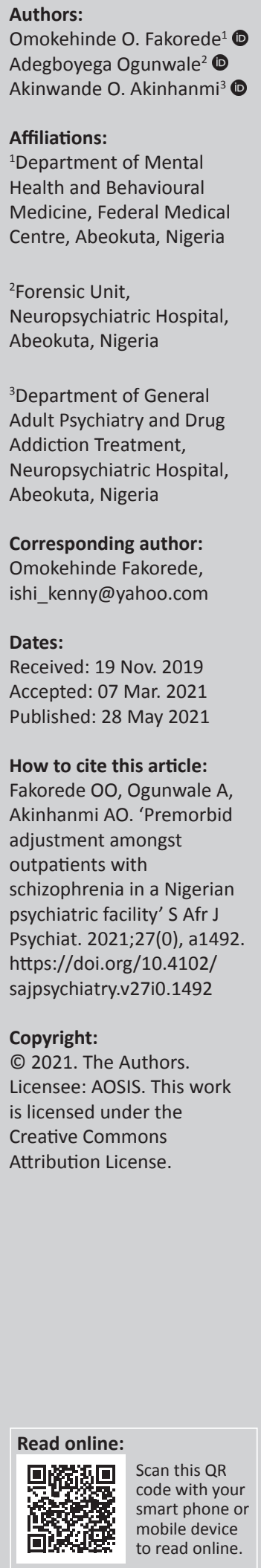

Authors:

\section{Affiliations:}

Department of Mental Medicine, Federal Medical

Centre, Abeokuta, Nigeria

${ }^{2}$ Forensic Unit

Neuropsychiatric Hospital,

${ }^{3}$ Department of General

Adult Psychiatry and Drug

Corresponding author:

Omokehinde Fakorede,

Dates:

Accepted: 07 Mar. 2021

How to cite this article: Fakorede OO, Ogunwale A, Akinhanmi AO. 'Premorbid djustment amongst outpatients with schizophrenia in a Nigerian psychiatric facility' S Afr https://doi.org/10.4102/

Copyright:

(C) 2021. The Authors Licensee: AOSIS. This work is licensed under the Creative Commons
Background: Studies from developed countries have shown that poor premorbid adjustment in patients with schizophrenia is associated with poor outcome. However, similar studies in developing countries like Nigeria are few despite the stability of schizophrenia prevalence across cultures.

Aim: The aim of this study was to assess the prevalence and correlates of poor premorbid adjustment amongst outpatients with schizophrenia.

Setting: The Neuropsychiatric Hospital, Abeokuta in Ogun State, Nigeria.

Methods: The premorbid adjustment of 300 outpatients with schizophrenia was assessed using the premorbid adjustment scale. Pattern and severity of psychosis, overall illness severity, global assessment of functioning and socio-demographic factors were investigated as correlates of premorbid functioning.

Results: About half (53.3\%) of the respondents had poor premorbid adjustment and most of them were males (56.9\%). Poor premorbid adjustment was associated with male gender $\left(\chi^{2}=7.81, p=0.005\right)$ whilst good premorbid adjustment was associated with no or borderline illness severity $\left(\chi^{2}=8.26, p=0.016\right)$ as well as no or mild impairment in functioning $\left(\chi^{2}=7.01\right.$, $p=0.029)$ amongst the respondents. Positive, negative and general symptomatology were predicted by premorbid adjustment at different developmental stages.

Conclusion: Consistent with existing literature, poor premorbid adjustment was prevalent amongst patients with schizophrenia in this study and was associated with male gender, poorer clinical outcomes and greater illness severity. Mental health promotion and other preventative approaches are recommended as possible early intervention strategies in dealing with schizophrenia.

Keywords: premorbid adjustment; premorbid functioning; schizophrenia; psychosis; functioning; out-patients; Nigeria.

\section{Introduction}

Premorbid adjustment in relation to mental disorder has been defined by various authors. Philips ${ }^{1}$ defined the concept as the extent to which an individual had fulfilled the appropriate expectations considering gender and age prior to the development of the illness, whilst Cannon-Spoor ${ }^{2}$ described it as a measure of an individual's attainment of age-appropriate developmental and social milestones from childhood until about 6 months before onset of illness. Scholars have reiterated the prognostic importance of premorbid adjustment in schizophrenia. 2,3

Generally, it has been shown that most patients with schizophrenia had poor premorbid adjustment ${ }^{4,5}$ and this has been associated with brain atrophy, ${ }^{6}$ ventricular enlargement, ${ }^{7}$ attention deficits, ${ }^{8}$ verbal reasoning difficulties,${ }^{9}$ negative symptoms,${ }_{1}^{10}$ poor treatment response, ${ }^{11}$ prolonged hospital stay ${ }^{12}$ and poor functioning ${ }^{13}$. It is important to note that the above findings were observed amongst people of European descent and there appears to be only one relevant study on the subject amongst Nigerian patients with schizophrenia. ${ }^{14}$ It was a comparative study on the premorbid social adjustment of 38 patients with schizophrenia and 20 with mania. The authors found that the patients with schizophrenia consistently tended to have poorer premorbid adjustment compared with patients with mania, and this was significant with the domain of 'highest level of functioning'. Amongst the group with schizophrenia, the men had poorer premorbid functioning than the women, and poor premorbid functioning was associated with the number of years of formal education. 
Some of the limitations of this work are the rather small sample size and narrow investigation for possible correlates of poor premorbid adjustment. Whilst the study above did not assess scholastic and occupational premorbid functioning for some developmental stages, utilised a small sample size of 58 in all and compared the findings amongst two clinical groups - schizophrenia and mania - there is a need to carry out a study that only focuses on schizophrenia, is comprehensive (assesses beyond the social functioning of the patients) and explores the relationship between the variable of interest and significant clinical parameters (psychosis pattern illness severity and current functioning). These correlates may aid the retrospective diagnosis of poor premorbid adjustment as well as prognosticate illness outcome in patients with schizophrenia. Findings on prepsychotic and early psychotic illness constitute significant prognostic parameters in the management of psychotic disorders. However, such studies amongst Nigerian patients with schizophrenia are few. Therefore, studies on schizophrenia and related concepts from Nigeria becomes imperative for scientific knowledge and comparative purpose. Our study therefore aimed to study 'premorbid adjustment' and its correlates amongst a sample of Nigerian patients with schizophrenia, as well as investigate the contribution of the clinical variables at different socio-sexual stages of premorbid functioning.

\section{Methods}

This cross-sectional research was part of a larger study conducted amongst outpatients with schizophrenia, at the Neuropsychiatric Hospital, Abeokuta in Ogun State, Nigeria. Individuals who fulfilled the inclusion criteria were recruited (through consecutive sampling method) for the study over a 3-month period (January-March 2014). The inclusion criteria were being within the age bracket of 18-64 years, having a clinical diagnosis of schizophrenia and having been an outpatient of the hospital for at least 1 year.

An estimated sample size of 256 was derived based on the prevalence of $78 \%$ of social disability amongst outpatients with schizophrenia in the same study setting 21 years ago. ${ }^{15}$ This was calculated using the Cochran's minimum sample size formula ${ }^{16}$ :

$n=\frac{Z^{2} p q}{d^{2}}$

[Eqn 1]

where:

$n=$ the desired sample size when the population is $>10000$

$Z=$ the standard normal deviate, 1.96 at $95 \%$ confidence level

$p=$ the proportion of social disability amongst outpatients with schizophrenia, $78 \%{ }^{15}$

$q=1.0-p=0.22$

$d=$ degree of accuracy desired usually set at 0.05 .

Therefore:

$n=\underline{1.96 \times 1.96 \times 0.78 \times 0.22}$

$0.05 \times 0.05$ $n=263.68$

However, because the study population is below 10000 , the true sample size $\left(n_{f}\right)$ was estimated as:

$n_{f}=\frac{n}{1+\frac{(n)}{(N)}}$

where:

$n_{f}=$ the desired sample size when the study population is less than 10000

$n=$ the desired sample size when the study population is more than 10000 , that is, 264

$N=$ the estimated study population which is 9417 , the population of outpatients within the age of 18-64 years and with the diagnosis of schizophrenia in the year $2010 .{ }^{17}$

Therefore:

$n_{f}=\frac{264}{1+\frac{264}{9417}}$

[Eqn 4]

$n f=256$

This was then oversampled by $15 \%$ to account for refusal and non-response, which gave a total of 294.4-300.

During the data collection, a total number of 316 patients who met the inclusion criteria were approached. Using the World Health Organization International Classification of Diseases as a diagnostic instrument to confirm the diagnosis of schizophrenia amongst the respondents, 11 did not meet the diagnostic criteria whilst 5 did not give consent to participate. The remaining 300 patients who were positive for schizophrenia and gave their consent were recruited for the study.

The study was approved by the Neuropsychiatric Hospital Aro Health Research Ethics Committee, and all respondents consented to participate in the study. Patients who met the inclusion criteria were assessed for their socio-demographic factors, level of premorbid adjustment, severity and pattern of psychosis, overall severity of psychosis and their current level of functioning in that order.

Participant's socio-demographic and clinical characteristics were assessed using the socio-demographic questionnaire which contained close-ended questions.

The premorbid adjustment scale (PAS) ${ }^{18}$ was used to assess the level of premorbid adjustment of the patients in this study. The scale has five subscales - childhood (up to age 11), early adolescence (12-15 years), late adolescence (17-18 years), adulthood (19 years and above) and general subscales. The general subscale is not particularly useful in research because 
it does not assess premorbid function per se, and it is biased towards the young age group. ${ }^{19}$ Therefore, it was also not used in this work. Previous authors used the Israeli Draft Board's Assessment as a comparative tool with the PAS and the latter demonstrated good predictive and concurrent validity. It yielded 0.76 and 0.80 for the social-related scales and 0.71 and 0.72 for the academic-related scales. ${ }^{12}$ Furthermore, a Nigerian study by Gureje et al. ${ }^{14}$ reported a value of 0.773 as the Cronbach's $\alpha$ for internal consistency. The adapted instrument used in this work contains 17 items each of which has a phrased description for scoring. Each scale assesses an individual's social accessibility, peer relationships, functioning beyond the nuclear family and capacity to form intimate socio-sexual ties prior to the onset of the illness. The scale's reliability using Cronbach's $\alpha$ ranged between 0.72 and 0.79 . Scores for each subscale is calculated by dividing the obtained score by the total obtainable score for that subscale. The overall score is an average of the scores obtained on all the developmental scales that apply to each individual. Each item on each subscale is scored on a Likert scale of 0 to 6 with 0 and 6 representing the 'healthiest' and 'least healthy' ends, respectively. The median PAS score in this sample was found to be 0.29 . Scores below 0.29 were categorised as good premorbid adjustment whilst scores of 0.29 and above are grouped as poor premorbid adjustment. ${ }^{20}$ A Nigerian study which validated the instrument reported an (Cronbach's) internal consistency of $0.773 .^{14}$

The positive and negative syndrome scale (PANSS) ${ }^{21}$ was used to assess the pattern of psychosis (positive symptoms, negative symptoms or general psychiatric symptoms). The PANSS is a 30-item, 7-point rating instrument with 18 items adapted from the brief psychiatric rating scale ${ }^{22}$ and 12 from the psychopathology rating schedule. ${ }^{23}$ It relates the positive and negative symptoms of schizophrenia to the global psychopathology. Thirty items are subdivided into positive (7 items), negative (7 items) and general psychopathology (16 items) subscales, with each item rating point representing increasing levels of psychopathology: 1 = absent, 2 = minimal, $3=$ mild, $4=$ moderate, $5=$ moderate severe, $6=$ severe and 7 = extreme. The score ranges from 7 to 49 for both the positive and negative subscales and 16 to 112 for the general psychopathology subscale. The subtotal scores for each of the subscales were calculated and then summed to make the total score. The minimum total score is 30 and the maximum total score is 210. Higher scores reflect higher severity of psychosis. At its development, the a coefficients for the positive and negative scales were found to be 0.73 and 0.83 , respectively. ${ }^{24}$ For the positive, negative, composite and general psychopathology scales, the test-retest Pearson correlations were $0.80(p<0.001), 0.68(p<0.01), 0.66(p<0.01)$ and $0.60(p<0.02)$, respectively. ${ }^{25}$ In a South African study, the inter-rater reliability was also found to be good, $r=0.88 .^{26}$ The instrument has, however, been used amongst Nigerian patients with schizophrenia. ${ }^{27}$ The PANSS testretest reliability obtained in our preliminary validation study for the positive, negative and total subscales was good ( $n=0.985,0.980$ and $0.797, p<0.001$, respectively).
The severity subscale of the clinical global impression (CGI) ${ }^{28}$ measures the overall severity of psychosis. It provides information as regards the overall functioning of patients either prior to or after instituting medications. The rater is expected to consider the patient's history, symptoms, illness severity, level of distress, behaviour and the impact of the symptoms on the patient's functioning. The CGI has three subscales: the first (CGI-Severity, CGI-S) rates illness severity; the second, CGI-Improvement (CGI-I) rates the change from the initiation of treatment; and the third rates the efficacy index (CGI-E), which measures the therapeutic response. Only CGI-S is useful for a cross-sectional study ${ }^{29}$ as the current work. The other subscales are useful in prospective and drug-intervention studies, respectively. ${ }^{29}$ With the CGI-S, ratings are done on a 7-point scale of 1-7 ( 1 = normal, not at all ill; $2=$ borderline mentally ill; $3=$ mildly ill; $4=$ moderately ill; $5=$ markedly ill; $6=$ severely ill and $7=$ amongst the most extremely ill patients) based upon observed and reported symptoms, behaviour and function in the past 7 days. It has been shown to correlate well with other standard instruments such as the brief psychiatric rating scale ${ }^{30}$ and has good psychometric properties: high face validity ${ }^{28}$ and good inter-rater reliabilities of 0.66 and 0.51 for the CGI-S and the CGI-I subscales, respectively. ${ }^{30}$ It has been extensively used ${ }^{31}$ even in this environment. ${ }^{32}$ The test-retest reliability we conducted in our preliminary validation study was $0.860, p<0.001$.

The global assessment of functioning (GAF) ${ }^{33}$ was used to evaluate the symptom description and socio-occupational functioning in this population sample. It is a product of serial modifications of the health-sickness rating ${ }^{34}$ which was later revised to the global assessment scale. ${ }^{35}$ The GAF was eventually introduced, after the global assessment scale, as a new rating scale for the assessment of the overall psychiatric disturbance on Axis V of the Diagnostic and Statistical Manual of Mental Disorders ${ }^{33}$ (American Psychiatric Association, 1987). It is a 100-scale instrument which is divided into 10 ranges of functioning of anchor descriptions, with each decile having two components: general descriptions of symptom severity and behavioural descriptors of socialoccupational functioning. The patient is rated relative to the deciles within which he or she falls, depending on the symptom severity or the level of function within that range. The exact GAF score is then determined from within the decile and the final score is the most severe assessment of either the psychological symptoms or the social-occupational level of function. A score of 0 is assigned if there is not enough information to make an assessment. In a study conducted by Hilsenroth et al. ${ }^{36}$ at a university-based outpatient community clinic, its inter-rater reliability was found to be excellent $(r=0.86)$ whilst its relationship to the global assessment of relational functioning was significant $(r=0.60, P<0.0001)$ as was its relationship to the social and occupational functioning assessment scale $(r=0.60, P<0.0001)$. This instrument has been used in various studies in this environment. ${ }^{37,38}$ In this work, the score obtained for each respondent was categorised into no to mild impairment (61-100), serious to moderate 
impairment (41-60) and severe impairment (1-40) in functioning. The test-retest reliability we conducted in a preliminary validation study was $0.943, p<0.001$.

\section{Statistical analysis}

The Statistical Package for Social Sciences (version 16.0) was used to analyse the data obtained in this work.

Categorical data from qualitative variables were expressed as percentages of the total whilst continuous data of numerical variables were expressed in means (and standard deviations). However, data of 'premorbid adjustment' which are continuous were further dichotomised into 'good' and 'bad' adjustment using the median score. ${ }^{39}$

Chi-square analysis was done to determine the association between premorbid adjustment and the other variables (both socio-demographic and clinical).

The variables that demonstrated significance in the tests of association (gender, illness severity and global assessment of functioning) were entered as predictor variables in a multivariate logistic regression, whilst the outcome variable remained the premorbid adjustment. The derived logistic regression odds ratio was presented with $95 \%$ confidence intervals.

The contribution of premorbid adjustment at different sociosexual stages to the clinical variables was investigated using multiple linear regression.

The level of significance for all statistical tests was $p<0.05$.

\section{Results}

The study respondents were 300 in total: 148 males and 152 females. The mean age of the respondents was 41.9 (standard deviation $[\mathrm{SD}]=10.1$ ) years, with a range of 20-64 years and most were of the Yoruba tribe $(92.7 \%)$, Christians (74.4\%), unmarried (69.3\%) with secondary level of education (43.3\%) and employed (Table 1).

The mean age (SD) of the onset of illness, duration of illness, duration of untreated psychosis, number of episodes, number of previous hospitalisation, total PANSS score and GAF score were $28.4 \pm 8.5(14-60)$ years, $13.5 \pm 8.6(2-40)$ years, $187.03 \pm$ 155.05 (6-1300) weeks, $2.6 \pm 1.0(0-5), 0.9 \pm 1.0,33.85 \pm 8.27$ (30-106) and $76.25 \pm 14.57$ (21-85), respectively (Table 2).

The mean overall premorbid adjustment score was 0.34 , whilst the median was 0.29 . Using the median to split into 'good' and 'poor premorbid' adjustment, 53.3\% of the respondents had poor premorbid adjustment (Figure 1).

Poor premorbid adjustment was significantly associated with the male gender, whilst good premorbid adjustment was associated with no to borderline illness as well as no to mild impairment (Table 3).
TABLE 1: The socio-demographic characteristics of the respondents.

\begin{tabular}{|c|c|c|}
\hline Variables & $N$ & $\%$ \\
\hline \multicolumn{3}{|l|}{ Gender } \\
\hline Male & 148 & 49.3 \\
\hline Female & 152 & 50.7 \\
\hline \multicolumn{3}{|l|}{ Age (years) } \\
\hline 20-39 & 136 & 45.4 \\
\hline $40-59$ & 149 & 49.6 \\
\hline 60 and above & 15 & 5.0 \\
\hline Mean \pm SD & $41.9 \pm 10.05$ & \\
\hline \multicolumn{3}{|l|}{ Ethnicity } \\
\hline Yoruba & 278 & 92.7 \\
\hline Other tribes & 22 & 7.3 \\
\hline \multicolumn{3}{|l|}{ Religion } \\
\hline Christianity & 223 & 74.4 \\
\hline Islam & 76 & 25.3 \\
\hline Trado-African & 1 & 0.3 \\
\hline \multicolumn{3}{|l|}{ Marital status } \\
\hline Single & 119 & 39.7 \\
\hline Married & 92 & 30.7 \\
\hline Separated/divorced & 66 & 22 \\
\hline Widowed & 23 & 7.6 \\
\hline \multicolumn{3}{|l|}{ Highest educational status } \\
\hline None & 16 & 5.3 \\
\hline Primary & 56 & 18.7 \\
\hline Secondary & 130 & 43.3 \\
\hline Tertiary and postgraduate & 98 & 32.7 \\
\hline \multicolumn{3}{|l|}{ Employment status } \\
\hline Unemployed & 100 & 33.3 \\
\hline Student/apprentice & 24 & 8.0 \\
\hline Employed & 168 & 56 \\
\hline Retired & 8 & 2.7 \\
\hline
\end{tabular}

TABLE 2: Clinical characteristics of the respondents.

\begin{tabular}{lcc}
\hline Variables & Mean & SD \\
\hline Age at illness onset (years) & 28.4 & 8.5 \\
Total illness duration (years) & 13.5 & 8.6 \\
DUP (weeks) & 187 & 155.1 \\
Number of episodes & 2.6 & 1.0 \\
Number of previous hospitalisation & 0.9 & 1.0 \\
PANSS & & \\
Positive subscale & 8.7 & 3.7 \\
Negative subscale & 8.5 & 3.8 \\
General subscale & 16.6 & 2.7 \\
Total & 33.9 & 8.3 \\
CGI & 1.76 & 1.2 \\
GAF & 76.3 & 14.6 \\
Overall premorbid adjustment & & \\
Mean & 0.34 & 0.2 \\
Median (IQR) & 0.29 & 0.2 \\
Childhood premorbid adjustment & 0.32 & 0.2 \\
Early adolescence premorbid adjustment & 0.36 & 0.1 \\
Late adolescence premorbid adjustment & 0.34 & 0.1 \\
Adulthood premorbid adjustment & 0.28 & 0.2 \\
\hline
\end{tabular}

DUP, duration of untreated psychosis; PANSS, positive and negative syndrome scale; CGI, clinical global impression; IQR, interquartile range; SD, standard deviation.

Of the three variables investigated, only the gender added significantly to the prediction (Table 4). The odds of having a poor premorbid adjustment was twofold greater for males as opposed to females (Table 4).

As shown in Table 5, multiple linear regression models were estimated to predict the severity of psychosis (based on PANSS 
scores), overall illness severity and current level of functioning from four premorbid developmental stages amongst the participants. With regard to the positive subscale of the PANSS, the developmental stages accounted for only $6.7 \%$ of the variability of the positive symptomatology. However, only the adulthood stage demonstrated a significant prediction to the model $(p=0.003)$. Negative PANSS score was independently

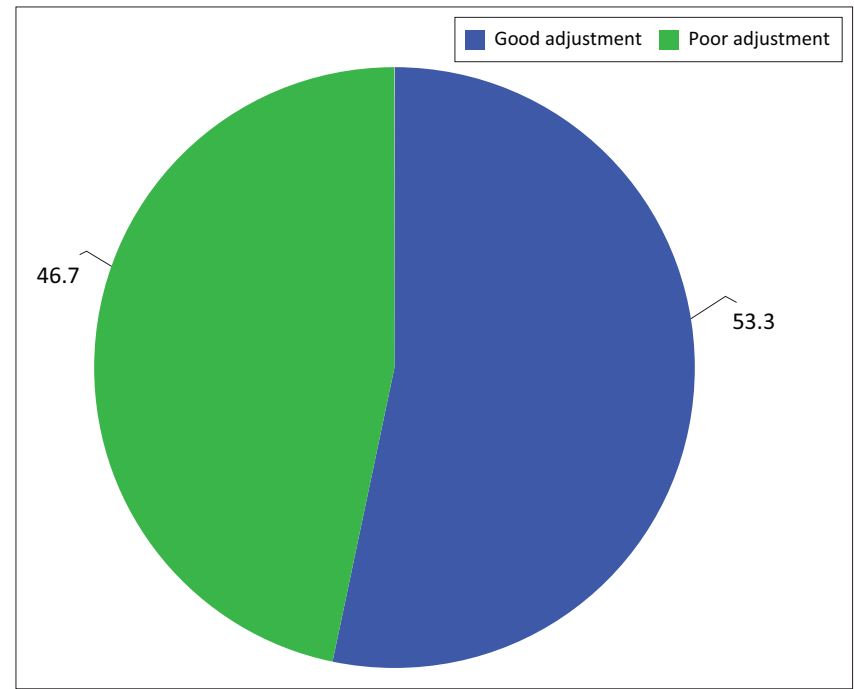

FIGURE 1: Overall premorbid adjustment. predicted by childhood, late adolescence and adulthood premorbid functioning $(p=0.000)$, explaining $16.8 \%$ of the variability in the negative symptomatology. In terms of general PANSS, the developmental stages only accounted for $6.4 \%$ of the variability in the non-specific symptomatology.

Childhood and late adolescence were statistically significant in terms of their predictive power $(p=0.001)$. Total PANSS scores were predicted by childhood, late adolescence and adulthood premorbid functioning $(p=0.001)$. The premorbid adjustment explained $14 \%$ of the variability in the global psychotic phenomena.

The prediction model for the relationship between premorbid functioning and global illness severity was not significant $(F=3.56, p=0.08)$ although adulthood premorbid functioning significantly explained $5.1 \%$ of the variance in illness severity $(p=0.012)$. Similarly, global functioning was predicted by adulthood premorbid functioning scores $(p=0.011)$ and the overall model was significant $(F=4.25, p=0.002)$. Premorbid functioning accounted for $6 \%$ of the variance in global functioning.

\section{Discussion}

This study aimed to determine the prevalence of poor premorbid adjustment as well as its correlates amongst

TABLE 3: Socio-demographic and clinical correlates of premorbid adjustment.

\begin{tabular}{|c|c|c|c|c|c|c|c|}
\hline \multirow[t]{2}{*}{ Variables } & \multicolumn{2}{|c|}{ Good premorbid adjustment } & \multicolumn{2}{|c|}{ Poor premorbid adjustment } & \multirow[t]{2}{*}{$\chi^{2}$} & \multirow[t]{2}{*}{$d f$} & \multirow[t]{2}{*}{$p$} \\
\hline & $n$ & $\%$ & $n$ & $\%$ & & & \\
\hline \multicolumn{8}{|l|}{ Gender } \\
\hline Male & 57 & 40.7 & 91 & 56.9 & 7.81 & 1 & $0.005^{*}$ \\
\hline Female & 83 & 59.3 & 69 & 43.1 & - & - & - \\
\hline \multicolumn{8}{|c|}{ Highest educational achievement } \\
\hline Below tertiary education & 94 & 67.1 & 108 & 67.5 & - & - & - \\
\hline Tertiary education and above & 46 & 32.9 & 52 & 32.5 & 0.04 & 1 & 0.948 \\
\hline \multicolumn{8}{|l|}{ Employment status } \\
\hline Employed & 83 & 59.3 & 85 & 53.1 & 1.15 & 1 & 0.284 \\
\hline Unemployed & 57 & 40.7 & 75 & 46.9 & - & - & - \\
\hline \multicolumn{8}{|l|}{ Severity of illness } \\
\hline Not ill/borderline & 118 & 84.2 & 113 & 70.6 & 8.26 & 1 & $0.016^{*}$ \\
\hline Mild/moderate & 18 & 12.9 & 35 & 21.9 & - & - & - \\
\hline Marked/severe & 4 & 2.9 & 12 & 7.5 & - & - & - \\
\hline \multicolumn{8}{|l|}{ History of hospitalisation } \\
\hline Yes & 75 & 53.6 & 73 & 45.6 & 1.89 & 1 & 0.17 \\
\hline No & 65 & 46.4 & 87 & 54.4 & - & - & - \\
\hline \multicolumn{8}{|c|}{ Global assessment of functioning } \\
\hline No/mild impairment & 128 & 91.5 & 129 & 80.6 & - & - & - \\
\hline Moderate impairment & 10 & 7.1 & 5 & 3.2 & 7.01 & 2 & $0.029 *$ \\
\hline Severe impairment & 2 & 1.4 & 26 & 16.2 & - & - & - \\
\hline
\end{tabular}

$*, p<0.05$.

TABLE 4: Independent correlates of premorbid adjustment.

\begin{tabular}{|c|c|c|c|c|c|c|c|c|}
\hline \multirow[t]{2}{*}{ Variable } & \multirow[t]{2}{*}{$B$} & \multirow[t]{2}{*}{ SE } & \multirow[t]{2}{*}{ Wald } & \multirow[t]{2}{*}{ Sig. } & \multirow[t]{2}{*}{ OR } & \multicolumn{2}{|c|}{$95 \% \mathrm{Cl}$} & \multirow[t]{2}{*}{ Nagelkerke $R^{2}$} \\
\hline & & & & & & Lower & Upper & \\
\hline \multicolumn{9}{|l|}{ Gender } \\
\hline Male & 0.814 & 0.254 & 10.262 & 0.001 & 2.3 & 1.37 & 3.71 & $0.078^{*}$ \\
\hline Female & - & - & - & - & - & - & - & - \\
\hline Severity of illness & 0.162 & 0.233 & 0.486 & 0.486 & 1.2 & 0.75 & 1.86 & - \\
\hline Global assessment of functioning & -0.122 & 0.207 & 0.346 & 0.557 & 0.89 & 0.59 & 1.33 & - \\
\hline
\end{tabular}

$*, p<0.05$. 
TABLE 5: Linear regression modelling of the association between socio-sexual stages of premorbid adjustment and illness severity.

\begin{tabular}{|c|c|c|c|c|c|c|}
\hline Variable & $\beta \dagger$ & $t$ & $p^{*}$ & $\boldsymbol{F}$ & $p^{*}$ & $R^{2}$ \\
\hline Positive subscale PANSS & & & & 4.775 & 0.001 & 0.067 \\
\hline Childhood & 0.167 & 1.652 & 0.100 & & & \\
\hline Early adolescence & 0.12 & 0.991 & 0.322 & & & \\
\hline Late adolescence & -0.335 & -2.804 & $0.005^{*}$ & & & \\
\hline Adulthood & 0.242 & 3.016 & $0.003 *$ & & & \\
\hline Negative subscale PANSS & & & & 13.442 & 0 & 0.168 \\
\hline Early adolescence & 0.061 & 0.5333 & 0.595 & - & - & - \\
\hline Late adolescence & -0.401 & -3.555 & $0.000^{*}$ & - & - & - \\
\hline Adulthood & 0.275 & 3.634 & $0.000^{*}$ & - & - & - \\
\hline General subscale PANSS & & & & 5.639 & 0 & 0.078 \\
\hline Childhood & 0.345 & 3.43 & $0.001^{*}$ & - & - & - \\
\hline Early adolescence & -0.047 & -0.392 & 0.695 & - & - & - \\
\hline Late adolescence & -0.407 & -3.431 & $0.001^{*}$ & - & - & - \\
\hline PANSS total & & & & 10.861 & 0 & 0.14 \\
\hline Childhood & 0.377 & 3.874 & $0.000^{*}$ & - & - & - \\
\hline Early adolescence & 0.067 & 0.576 & 0.565 & - & - & - \\
\hline Late adolescence & -0.46 & -4.016 & $0.000 *$ & - & - & - \\
\hline Adulthood & 0.299 & 3.88 & $0.000^{*}$ & - & - & - \\
\hline CGI & & & & 3.557 & 0.08 & 0.051 \\
\hline Childhood & 0.152 & 1.49 & 0.138 & - & - & - \\
\hline Early adolescence & 0.028 & 0.232 & 0.817 & - & - & - \\
\hline Late adolescence & -0.167 & -1.383 & 0.168 & - & - & - \\
\hline Adulthood & 0.204 & 2.519 & $0.012^{*}$ & - & - & - \\
\hline GAF & & & & 4.246 & 0.002 & 0.06 \\
\hline Childhood & -0.193 & -1.897 & 0.059 & - & - & - \\
\hline Early adolescence & -0.029 & -0.24 & 0.811 & - & - & - \\
\hline Late adolescence & 0.194 & 1.622 & 0.106 & - & - & - \\
\hline
\end{tabular}

$*, p<0.05$.

$\dagger$, Standardised $\beta$.

PANSS, positive and negative syndrome scale; CGI, clinical global impression; GAF, global assessment of functioning.

Nigerian patients with schizophrenia. It represents one of the few studies that have focused on the subject amongst patients in the developing countries.

The prevalence of poor premorbid adjustment in this sample is slightly more than $50 \%$ and is consistent with earlier studies conducted amongst Nigerians ${ }^{14}$ and non-Nigerians. ${ }^{4,5,18}$ A possible explanation as proposed in some studies is the role of the neurodevelopmental hypothesis. ${ }^{40,41,42}$ These authors posited that insults to the immature brain (during the premorbid period) result in non-progressive damage to the brain with resultant psychotic symptoms characteristic of schizophrenia. However, why a substantial number of patients had good premorbid adjustment and still had the disease may be accounted for by other aetiological factors in schizophrenia as explained by its multifactorial basis. ${ }^{43,44}$

Of all the variables investigated, poor premorbid adjustment was significantly associated with male gender. Studies ${ }^{14,45,46,47}$ have shown that males with schizophrenia tend to have poorer premorbid functioning than their female counterparts. Other authors ${ }^{19}$ have also posited that males experience more decline in their premorbid functioning over the epoch ages. The associative and even predictive association found between both in this work lends credence to the current established findings. This may be explained by the fact that females generally exhibit better premorbid social functioning, ${ }^{19}$ have higher frequency of marital stability premorbidly ${ }^{19}$ and have later age of illness onset. ${ }^{13}$ Lenroot and Giedd ${ }^{48}$ as well as Tuszynski and others ${ }^{49}$ have also suggested that females' earlier maturity - both cognitively and emotionally $-{ }^{48,49}$ might have protected them from the insult to the brain at the same period in which their male counterparts were vulnerable. Even if the insult occurred later, they might have matured beyond the age in which such insult would have a deleterious effect on their premorbid functioning.

Findings from the multiple linear regression analysis in this study demonstrated that the later epoch ages (late adolescence and adulthood) consistently demonstrated a significant relationship with the positive, negative and generalised subscales. Consistent with this picture, Larsen et al. ${ }^{50}$ in a study conducted amongst 40 people reported that the age epochs close to the onset of the illness had worse premorbid adjustment scores than the earlier developmental periods, that is, the level of premorbid adjustment seemed to deteriorate as the patient advanced in age. They proposed that although the insult could have occurred during the earliest period of a patient's life, illness development occurs around the mid-adolescent period but fully takes off around the late adolescent/adulthood period with the resultant 
clinical expression almost immediately. This explanation seems plausible, given the results obtained in our study.

Studies have shown that poor premorbid adjustment is associated with severity of symptoms $\mathrm{s}^{51,52}$ and may even be a predictor of the latter..$^{51}$ It was, therefore, not surprising when this study revealed the association between good premorbid adjustment and no or bordeline illness severity. This means that patients who attained good socio-sexual functioning before the onset of the illness seemed not to be so ill or unable to function in general spheres of life as at the time of this survey. As a corollary, the association between poor premorbid adjustment and poor current functioning has been documented. ${ }^{53}$

Overall, this work has highlighted the premorbid adjustment of a group of outpatients with schizophrenia. However, given the modest amounts of explanatory power attributable to premorbid functioning at different epoch ages in this study, it may be reasonable to suggest that other unmeasured factors play active roles in the evolution of schizophrenia. Thus, premorbid functioning need not be seen as the singular predictor of illness or illness outcome in schizophrenia. Despite the strengths of this work, other potential variables related to premorbid functioning such as investigation for biomarkers or neurological abnormalities were not conducted. Also, the possible history of febrile convulsions, seizure disorder, head trauma or psychoactive substance use prior to the onset of the illness was not obtained. These may also have been important contributors to the poor premorbid functioning amongst the sample. . $33,54,55,56^{-5}$

As noted earlier, a large proportion of this study population appeared to be stable both clinically and functionally. Beyond premorbid functioning, additional current factors such as adequate compliance with treatment and good family support may have contributed to this. It may, therefore, be important to investigate the role of some of these factors in illness severity in the future studies.

Cross-sectional studies do not provide a firm basis for determining the direction of causality of events. However, our focus on an earlier period helped to create a temporal ordering of premorbid adjustment and illness-related variables. Notwithstanding this, the possibility of recall bias cannot be ruled out in relation to premorbid functioning.

Furthermore, the results of the linear regression modelling of the relationship between illness severity and premorbid functioning must be interpreted with caution because of non-normality and non-linearity observed in both the illness severity measures and the PAS scores. Attempts at log transformation did not yield any normalisation of the data. Thus, whilst our analysis maintained fidelity to other assumptions of linear regression, the aforementioned assumptions were not followed.

It is also important to note that this work was conducted in a southwest Nigerian hospital with members of one ethnic group being over-represented. Thus, its generalisation to other parts of the country must be made with caution.

\section{Conclusion}

Poor premorbid adjustment was considerably present in this sample of patients with schizophrenia, and it was associated with male gender. In other words, clinicians should bear in mind that male patients with the illness may have likely had poorer premorbid functioning than females, especially in terms of marital and occupational achievement. These factors should also be considered when formulating rehabilitation goals as males may have lower room for improvement (and hence remission). Antenatal care providers should also be interested in exploring the other factors that may be responsible for insults to developing brains as well as their pathogenesis in the development of schizophrenia. Therefore, antenatal studies that encompass follow-up into adulthood period should be one of the focus of future researchers.

\section{Acknowledgements}

This manuscript was part of a larger study titled 'A Study On Disability Among Out-Patients With Schizophrenia Attending The Neuropsychiatric Hospital, Aro, Abeokuta, Ogun State'. The authors thank the patients who served as the respondents in this study as well as the management of the Neuropsychiatric Hospital, Aro who provided an enabling environment for the conduct of this research.

\section{Competing interests}

The authors declare that they have no financial or personal relationships that may have inappropriately influenced them in writing this article.

\section{Authors' contributions}

O.O.F. was responsible for the conceptualisation of the research, writing of the research proposal, data collection, data analysis, and writing and editing the manuscript. A.O. guided O.O.F. through all the stages of the work. In addition, he painstakingly handled the multivariate analysis and read through the proposal as well as the manuscript to ensure its worth to be published. A.O.A. made significant corrections to the proposal as well as the manuscript. He supervised the research from conceptualisation to publishing stage.

\section{Ethical considerations}

Ethical approval for this study was granted by the Neuropsychiatric Hospital Aro Research Ethics Committee (No. PR00/13).

\section{Funding information}

This research received no specific grant from any funding agency in the public, commercial or not-for-profit sectors. 


\section{Data availability}

Data sharing is not applicable to this article.

\section{Disclaimer}

The views and opinions expressed in this article are those of the authors and do not necessarily reflect the official policy or position of any affiliated agency of the authors.

\section{References}

1. Phillips L. Case history data and prognosis in schizophrenia. J Nerv Ment Dis. 1953 Jun;117(6):515-525. https://doi.org/10.1097/00005053-195306000-00004

2. Corripio I, Pérez V, Catafau A, Mena E, Carrió I, Alvarez E. Striatal D2 receptor binding as a marker of prognosis and outcome in untreated first-episode psychosis. Neuroimage. 2006;29(2):662-666. https://doi.org/10.1016/j.neuroimage. 2005.07.038

3. Schmael C, Georgi A, Krumm B, et al. Premorbid adjustment in schizophrenia An important aspect of phenotype definition. Schizophr Res. 2007 May 1;92(1): 50-62. https://doi.org/10.1016/j.schres.2007.01.016

4. Horton LE, Tarbox SI, Olino TM, Haas GL. Trajectories of premorbid childhood and adolescent functioning in schizophrenia-spectrum psychoses: A first-episode study. Psychiatry Res. 2015 Jun 30;227(2-3):339-346. https://doi.org/10.1016/j. study. Psychiatry Res.
psychres.2015.02.013

5. Tarbox SI, Brown LH, Haas GL. Diagnostic specificity of poor premorbid adjustment: Comparison of schizophrenia, schizoaffective disorder, and mood disorder with psychotic features. Schizophr Res. 2012;141(1):91-97. https://doi.org/10.1016/j. psychotic features. Schi
schres.2012.07.008

6. Weinberger DR, Canon-Spoor E, Potkin SG, Wyatt RJ. Poor premorbid adjustment and CT scan abnormalities in chronic schizophrenia. Am J Psychiatry. 1980;137:1410-1413. https://doi.org/10.1176/ajp.137.11.1410

7. Weinberger DR, DeLisi LE, Perman GP, Targum S, Wyatt RJ. Computed tomography in schizophreniform disorder and other acute psychiatric disorders. Arch Gen in schizophreniform disorder and other acute psychiatric disorders. Arch Gen Psychiatry. 1982
04290070014004

8. Silverstein M, Mavrolefteros G, Close D. Premorbid adjustment and neuropsychological performance in schizophrenia. Schizophr Bull. 2002;28(1): 157-165. https://doi.org/10.1093/oxfordjournals.schbul.a006918

9. Addington J, Addington D. Premorbid functioning, cognitive functioning, symptoms and outcome in schizophrenia. J Psychiatry Neurosci. 1993;18(1):18.

10. Haim R, Rabinowitz J, Bromet E. The relationship of premorbid functioning to illness course in schizophrenia and psychotic mood disorders during two years following first hospitalization. J Nerv Ment Dis. 2006;194(10):791-795. https:// doi.org/10.1097/01.nmd.0000240158.39929.e3

11. Rabinowitz J, Napryeyenko O, Burba B, et al. Premorbid functioning and treatment response in recent-onset schizophrenia: Prospective study with risperidone longacting injectable. J Clin Psychopharmacol. 2011;31(1):75-81. https://doi.org/ 10.1097/JCP.0b013e31820568c6

12. Brill N, Reichenberg $A$, Weiser $M$, Rabinowitz J. Validity of the premorbid adjustment scale. Schizophr Bull. 2008 Sep;34(5):981-983. https://doi. org/10.1093/schbul/sbm128

13. McGlashan TH. Premorbid adjustment, onset types, and prognostic scaling: Still informative? Schizophr Bull. 2008 Sep;34(5):801-805. https://doi.org/10.1093/ schbul/sbn073

14. Gureje $O$, Aderibigbe $Y$, Olley $O$, Bamidele R. Premorbid functioning in schizophrenia: A controlled study of Nigerian patients. Compr Psychiatry. 1994;35(6):437-440. https://doi.org/10.1016/0010-440X(94)90226-7

15. Gureje O, Bamidele R. Thirteen-year social outcome among Nigerian outpatients with schizophrenia. Soc Psychiatr Psychiatr Epidemiol. 1999;34(3):147-151. https://doi.org/10.1007/s001270050126

16. Sample size in statistics (how to find it): Excel, Cochran's formula, general tips [homepage on the Internet]. Statistics How To. [cited 2019 Nov 24]. Available from: https://www.statisticshowto.datasciencecentral.com/probability-and statistics/find-sample-size/

17. Home [homepage on the Internet]. [cited 2020 May 24]. Available from: https:// www.neuroaro.gov.ng/main/index.php/home

18. Cannon-Spoor E, Potkin SG, Wyatt RJ. Measurement of premorbid adjustment in chronic schizophrenia. Schizophr Bull. 1982 Jan 1;8(3):470-484. https://doi. org/10.1093/schbul/8.3.470

19. Van Mastrigt $S$, Addington J. Assessment of premorbid function in first-episode schizophrenia: Modifications to the premorbid adjustment scale. J Psychiatry Neurosci. 2002;27(2):92.

20. Hien D, Haas G, Cook H. Gender differences in premorbid social adjustment and intimacy motivation in schizophrenia. J Clin Psychol. 1998;54(1):35-48. https:// doi.org/10.1002/(SICI)1097-4679(199801)54:1\%3C35::AID-JCLP4\%3E3.0.CO;2-T

21. Kay SR, Opler LA, Lindenmayer JP. The positive and negative syndrome scale (PANSS): Rationale and standardisation. Br J Psychiatry Suppl. 1989;(7):59-67. https://doi.org/10.1192/S0007125000291514
22. Overall JE, Gorham DR. The brief psychiatric rating scale. 1962 [homepage on the Internet]. [cited 2020 May 24]. Available from: https://journals.sagepub.com/ doi/10.2466/pro.1962.10.3.799

23. Kay SR, Singh MM. A temporal measure of attention in schizophrenia and its clinical significance. $\mathrm{Br} J$ Psychiatry. 1974;125(0):146-151. https://doi. org/10.1192/bjp.125.2.146

24. Kay SR, Fiszbein A, Opler LA. The positive and negative syndrome scale (PANSS) for schizophrenia. Schizophr Bull. 1987;13(2):261-276. https://doi.org/10.1093/ schbul/13.2.261

25. Garrett HE. Statistics in psychology \& education [homepage on the Internet]. 6th ed. R.S. Woodworth: Amazon.com: Books. [cited 2020 May 24]. Available from: https://www.amazon.com/Statistics-Psychology-Education-Garrett-Woodworth/ dp/BO01PBLSOA

26. Burns JK, Jhazbhay K, Emsley R. Cannabis use predicts shorter duration of untreated psychosis and lower levels of negative symptoms in first-episode
psychosis: A South African study. Afr J Psychiatry. 2010;13(5):395-399. https:// psychosis: A South African study. Afr
doi.org/10.4314/ajpsy.v13i5.63106

27. Lawal R, Suleiman G, Onyeze B. Risperdone in the treatment of chronic schizophrenia. Niger Med Practit. 2004 Apr 29;44(1):11-18. https://doi.org/ 10.4314/nmp.v44i1.28675

28. Guy W. ECDEU assessment manual for psychopharmacology. Rockville, MD: US Department of Health, and Welfare; 1976. p. 534-537.

29. Forkmann T, Scherer A, Boecker M, Pawelzik M, Jostes R, Gauggel S. The clinical global impression scale and the influence of patient or staff perspective on outcome. BMC Psychiatry. 2011;11(1):83. https://doi.org/10.1186/1471-244X-11-83

30. Leucht S, Engel RR. The relative sensitivity of the clinical global impressions scale and the brief psychiatric rating scale in antipsychotic drug trials. Neuropsychopharmacology. 2006;31(2):406-412. https://doi.org/10.1038/sj. npp.1300873

31. Ak M, Yavuz KF, Lapsekili N, Türkçapar MH. Evaluation of burden in a group of patients with chronic psychiatric disorders and their caregivers. Düşünen Adam J patients with chronic psychiatric disord
Psychiatry Neurol Sci. 2012;25:330-337.

32. Adeyemi JD, Ohaeri JU, Obembe A, Odusanya OO, Dutheil Y. The efficacy and tolerability of paroxetine in the treatment of depression in Nigeria. Niger Q J Hosp Med. 1999;9(3):218-222. https://doi.org/10.4314/nqjhm.v9i3.12383

33. American Psychiatric Association. Diagnostic and statistical manual of mental disorders. Washington, DC: American Psychiatric Association; 1994. p. 143-146.

34. Luborsky L. Clinicians' judgments of mental health: A proposed scale. Arch Gen Psychiatry. 1962;7(6):407-417. https://doi.org/10.1001/archpsyc.1962.017200 60019002

35. Endicott J, Spitzer RL, Fleiss JL, Cohen J. The global assessment scale: A procedure for measuring overall severity of psychiatric disturbance. Arch Gen Psychiatry. for measuring overall severity of psychiatric disturbance. Arch Gen Psychiatry.

36. Hilsenroth MJ, Ackerman SJ, Blagys MD, et al. Reliability and validity of DSM-IV axis V. Am J Psychiatry. 2000;157(11):1858-1863. https://doi.org/10.1176/appi. ajp.157.11.1858

37. Adewuya AO, Makanjuola RO. Subjective life satisfaction and objective living conditions of patients with schizophrenia in Nigeria. Psychiatr Serv. 2010;61(3): 314-336. https://doi.org/10.1176/ps.2010.61.3.314

38. Lasebikan VO. Validation of yoruba version of family burden interview schedule (Y-FBIS) on caregivers of schizophrenia patients. ISRN Psychiatr. 2012;2012:165179. https://doi.org/10.5402/2012/165179

39. Dama M, Shah J, Norman R, et al. Short duration of untreated psychosis enhances negative symptom remission in extended early intervention service for psychosis. Acta Psychiatr Scand. 2019;140(1):65-76. https://doi.org/10.1111/acps.13033

40. Gourion D, Gourevitch R, Leprovost JB, lôo Olié JH, Krebs MO. Neurodevelopmental hypothesis in schizophrenia. L'Encephale. 2004;30(2):109-118. https://doi. hypothesis in schizophrenia. L'Enceph
org/10.1016/S0013-7006(04)95421-8

41. Owen MJ, O'Donovan MC, Thapar A, Craddock N. Neurodevelopmental hypothesis of schizophrenia. Br J Psychiatry. 2011;198(3):173-175. https://doi.org/10.1192/ bjp.bp.110.084384

42. Rund BR. The research evidence for schizophrenia as a neurodevelopmental disorder. Scand J Psychol. 2018;59(1):49-58. https://doi.org/10.1111/sjop.12414

43. Onaolapo AY, Onaolapo OJ. Schizophrenia aetiology and drug therapy: A tale of progressive demystification and strides in management. Adv Pharmacol Pharm. 2018;6(2):19-42. https://doi.org/10.13189/app.2018.060201

44. Saladino RE, Romeo G, Francone M, et al. Schizophrenia and HLA: Work in progress about typing usefulness and diagnostic therapeutic outlooks. 32nd European Immunogenetics and Histocompatibility Conference; 2018 May 9-12; Lido, Venice.

45. Childers SE, Harding CM. Gender, premorbid social functioning, and long-term outcome in DSM-III schizophrenia. Schizophr Bull. 1990;16(2):309-318. https:// doi.org/10.1093/schbul/16.2.309

46. Haahr UH, Larsen TK, Simonsen E, et al. Relation between premorbid adjustment, duration of untreated psychosis and close interpersonal trauma in first-episode psychosis. Early Interv Psychiatry. 2018;12(3):316-323. https://doi.org/10.1111/ eip.12315

47. Preston NJ, Orr KG, Date R, Nolan L, Castle DJ. Gender differences in premorbid adjustment of patients with first episode psychosis. Schizophr Res. 2002;55(3): 285-290. https://doi.org/10.1016/S0920-9964(01)00215-8

48. Lenroot RK, Giedd JN. Sex differences in the adolescent brain. Brain Cogn 2010;72(1):46-55. https://doi.org/10.1016/j.bandc.2009.10.008

49. Tuszynski J, Rietman E, Taylor S, Siegelmann H, Cavaglia M. Thermodynamic measures of human brain development from fetal stage to adulthood. BioRxiv. 2019;549360. 
50. Larsen TK, McGlashan TH, Johannessen JO, Vibe-Hansen L. First-episode schizophrenia: II. Premorbid patterns by gender. Schizophr Bull. 1996;22(2): 257-269. https://doi.org/10.1093/schbul/22.2.257

51. Dewangan RL, Singh P. Premorbid adjustment in predicting symptom severity and social cognitive deficits in schizophrenia. East Asian Arch Psychiatry. 2018;28(3):75.
52. Mahmoodi-Gharaei J, Basirnia A, Abedi N, et al. Association of premorbid adjustment with symptom profile and quality of life in first episode psychosis in a tertiary hospital in Tehran, Iran. Iran J Psychiatry. 2010;5(1):23.

53. Üçok A, Polat A, Çakır S, Genç A. One year outcome in first episode schizophrenia. Eur Arch Psychiatry Clin Neurosci. 2006;256(1):37-43. https://doi.org/10.1007/ s00406-005-0598-2 